\title{
Free to Decide: The Positive Moral Right to Reproductive Choice
}

Tess Johnson Oxford Uehiro Centre for Practical Ethics, University of Oxford, United Kingdom Correspondence address: tess.johnson@philosophy.ox.ac.uk

\begin{abstract}
The advent of novel assisted reproductive technologies (ARTs) has considerably expanded our sphere of control over our reproduction, and consequently, the scope of ethical debate surrounding reproductive choice. The now widespread availability of fertility services and genetic selection, in particular, raises questions regarding what free reproductive choice does and should entail. Whilst a negative form of the right to reproductive choice affords individuals only the right to non-interference from third parties in their reproductive decision-making, a positive moral right demands that its exercisability is ensured — that is, governments have a responsibility to offer support for individuals for whom reproductive choice is limited without additional aid. Here, I propose a new form of a positive moral right, which I argue can also effectively guide policy surrounding access to ARTs for fertility and genetic selection.
\end{abstract}

\section{INTRODUCTION}

The advent of novel assisted reproductive technologies (ARTs) has considerably expanded our sphere of control over our reproduction, and consequently, the scope of ethical debate surrounding reproductive choice. The widespread availability of genetic selection, in particular, raises questions regarding what reproductive choice does and should entail. Uses of preimplantation genetic diagnosis (PGD) for genetic selection, building on in vitro fertilization (IVF), force us to confront questions of whether a moral right to reproductive choice extends 
not only to the decision whether to have children and how many to have, but what type of children to have. Traditionally, reproductive choice has been grounded on negative liberty, entitling right-bearers simply the right to non-interference in one's reproductive decision-making by third parties. A basis of positive liberty, however, goes further: it demands that third parties facilitate individuals' exercising the freedom to choose. This facilitation requirement underpins the provision of (early) abortion in $71 \%$ of high-income countries (World Population Policies 2013 2013). However, when it comes to accessing ARTs such as PGD, the negative right conception continues to dominate, and has led to a widening gap between those who can exercise their right to make reproductive choices, and those who are unable to exercise the right, for example due to structural economic and social disadvantage that prevents them from being independently able to access or pay for these technologies. If reproductive choice (including access to ARTs) should be extended to all individuals, then the negative conception is inadequate.

The sufficiency of a negative right to reproductive choice (concerning ARTs) has been challenged before, yet feasible conceptions of an alternative, positive right have received far less attention. Here, I present a novel argument for the positive moral right to reproductive choice, entailing the provision of accessible reproductive technologies by governments for those who cannot access or use them without additional support. Applying the capabilities approach in this area, I take the position that the positive moral right to reproductive liberty (PMRRL) is justified by the centrality of reproductive choice to human flourishing and self-determination. This has implications both for reproductive choices to have a child, and for reproductive choices concerning what type of child to have.

To introduce the argument, I use John Robertson's Children of Choice (1994)—advocating a negative right to reproductive choice_-as a springboard to critique some key aspects of a negative moral right, in the first section. This insufficiency of the negative right is elaborated upon more generally in the second section, where I also explore how a positive moral right 
PRE-PUBLICATION VERSION - For published version, see the Kennedy Institute of Ethics Journal

avoids these objections. I explicate and justify PMRRL and the capabilities approach in the third section, and address possible objections. Finally, in the fourth section, PMRRL is applied to the question of access to ARTs, firstly regarding the choice to have a child (using IVF for fertility reasons), and secondly regarding the choice of which child to have (using PGD for genetic selection).

\section{ROBERTSON'S CONCEPTION OF PROCREATIVE LIBERTY}

Reproductive choice has been conceptualized in various ways in the literature, affording individuals more or less access to reproductive services, and consequently conferring more or less responsibility on governments to promote and protect citizens' reproductive decisionmaking. One influential conception has been suggested by John Robertson. I outline Robertson's conception here, and then argue against Robertson for a positive, exercisable right to reproductive choice for vulnerable groups via the provision of ARTs.

\section{Procreative Liberty}

Robertson conceptualizes free reproductive choice as 'procreative liberty', defined simply as the freedom to decide whether or not to have offspring, without government restriction of these choices. This is a negative conception of the right. He contends that procreative liberty holds priority over other ethical considerations regarding reproductive decisions, so that prospective parents should be free, as a matter of "respect and dignity at the most basic level", to engage in that "crucial self-defining experience" that reproductive choice represents (except where specific overriding concerns exist regarding the wellbeing of the future child) (Robertson 1994). It is, at first, unclear in Robertson's analysis whether this right to use PGD is also supported for the 
PRE-PUBLICATION VERSION - For published version, see the Kennedy Institute of Ethics Journal

selection of non-health-based traits. ${ }^{1}$ Initially he makes the case for such trait selection (1994, 152-153):

"if a person thought that she would realize those benefits [connection with future generations, and the pleasures of child rearing] only from a child with particular characteristics, then she should be free to select offspring to have those traits. The right to procreate would thus imply the right to take actions to assure that offspring have the characteristics that make procreation desirable or meaningful for that individual."

Later, however, Robertson instead limits the selection decisions supported by his conception of procreative liberty to those that can be expected to produce "normal, healthy" children (1994). Selective decisions that would constitute "diminishment" or "enhancement" are rejected "because they deviate too far from the experiences that make reproduction a valued experience" (Robertson 1994, 167). Thus, procreative liberty does not confer a moral right for individuals to use PGD to genetically select for or against any traits that would affect their decision whether or not to reproduce (within those traits expected not to harm the future child or society). Rather, their reproductive choice is further limited by a specific normative conception of that choice, such that procreative liberty only offers parents the freedom to not have specific, sanctioned reproductive choices interfered with by third parties.

\section{Third-party Interference with Rights}

Robertson uses procreative liberty to argue for the market availability of IVF and PGD at various points, emphasizing that infertile couples are "likely to feel inadequate at the core of their being" if unable to access IVF without interference $(1994,98)$. However, despite the strength of

\footnotetext{
${ }^{1}$ By non-health-based traits, I refer to those that may relate to competitive advantage, but are not usually considered to be determinants of disability or disease status, and do not require treatment.
} 
PRE-PUBLICATION VERSION - For published version, see the Kennedy Institute of Ethics Journal

his language, he does not extend procreative liberty to aiding such infertile couples in accessing these technologies. As later explained, this is because such provision may impinge upon others' freedoms, were they made through the taxation system to subsidize low-fertility couples' procreative choices. Robertson acknowledges the limitations of a negative right, however this only leads him to turn to legal rights, and claim that "the state presently has no constitutional obligation to provide those services" (Robertson 1994). Yet, our concern here is with moral rights, and any "tendency to tolerate unjust social arrangements," as Dorothy Roberts notes (1995), privileges individual autonomy and a legalistic definition over considerations of social justice that demand a positive right. When it comes to non-primary goods-that is, goods that are not essentially linked to human flourishing—social justice does not require making rights to such goods universally exercisable. However, accepted Rawlsian approaches acknowledge that governments of liberal democracies are morally obligated to support citizens' pursuit of primary goods_-goods that allow for their self-determined flourishing (Rawls 1999). Insofar as Robertson maintains that reproductive choice is essential to human flourishing, he must provide an argument as to why this does not place a responsibility on governments to ensure it is exercisable by citizens. Without drawing a morally relevant distinction between state-led third party interventions that the negative right denounces, and the interventions imposed by social conditions preventing access to IVF which he seems to find acceptable enough not to propose a positive right, Robertson's defense of his approach is questionable: he argues only against government interference with reproductive choice, and not with impediments to exercising the right that might arise because of structural disadvantage or other factors. This leaves the right to reproductive choice unprotected for large swathes of society, for whom its exercise is impossible. 
PRE-PUBLICATION VERSION - For published version, see the Kennedy Institute of Ethics Journal

The objections I have explored in the section above apply more generally to negative conceptions of the right to reproductive choice. Procreative liberty and similar conceptions cannot secure reproductive freedom for large sections of society, including members of disability communities, women in dependent situations, and those who are financially disadvantaged or geographically-isolated (Meilaender 1995; Purdy 1996a; Roberts 1995). It has been argued that the burdens faced particularly by disabled women seeking to reproduce are under-recognized: support is often required for these women to access reproductive services, and ableist attitudes in society mean that negative conceptions of reproductive freedom are inadequate to secure choice for such women (Knight 2017). Access to IVF to aid in reproduction may be made more difficult, whilst use of PGD may be facilitated under the assumption that women with heritable conditions will select against future children with their own condition, even when they may expect that the condition will contribute to the wellbeing of the child, for example by allowing them to better fit into a family with achondroplasia or deafness, and Little People or Deaf communities. In such cases, women may be effectively denied reproductive choice where their access to PGD relies on unwilling support workers' aid. If we have reason to believe that a certain disabled woman is incapable of raising her future child, or wishes to select for a condition that can plausibly be expected to cause the birth of a child whose life will be predictably worse in wellbeing terms than alternative choices of child, then limiting the right seems justified. However, outside these exceptions, there seems no plausible reason why the reproductive choices of disabled women should not be as able to be exercised as those of able-bodied individuals. Adequate support is not provided by a negative right, under current social conditions.

Rhonda Copelon highlights the link between rejection of these groups' rights and rejection of responsibility for social conditions by states, claiming that $(1990,46)$ : 
"[a negative right] is profoundly inadequate as a basis for reproductive and sexual freedom because it perpetuates the myth that the ability to effectuate one's choices rests exclusively on the individual, rather than acknowledging that choices are facilitated, hindered or entirely frustrated by social conditions. In doing so [it] exempts the state from responsibility for contributing to the material conditions and social relations that impede, and conversely, could encourage, autonomous decision-making."

Copelon's critique makes it clear that responsibility for remediable social conditions that prevent some from exercising their rights lies with government. Objectors may question the financial viability of alternative models that demand that governments remedy these conditions. For example, Robertson himself claims that "one can decry the disparities that exist and urge that society correct distributive inequities, however, without denying all persons the right to make these choices" $(1995,228)$. Here he sets up a dichotomy between permitting PGD, thereby allowing the advantaged to fully pursue certain reproductive goals, and prohibiting its use, thereby preventing anyone from fully pursuing certain reproductive goals. By removing the option of subsidization or provision of ARTs, advocates of the negative right narrow the field, making procreative liberty or other negative conceptions seem like the least bad of only two possible options-non-interference in reproductive choice, or denial of reproductive choice. Yet this is an overhasty move. We have evidence in adequately-funded healthcare systems that it is feasible for states to provided (limited) subsidies for ARTs already, including in the UK, the Netherlands, and Australia, among other countries, where between one and three IVF cycles are funded by governments (Van Hoyweghen et al. 2009). ${ }^{2}$

\footnotetext{
${ }^{2}$ Questions surrounding resource allocation in systems with more limited resources, however, do raise some challenges for the positive right, discussed further in the Objections section below.
} 


\section{A POSITIVE MORAL RIGHT TO REPRODUCTIVE LIBERTY}

In this section, I propose that the insufficiencies of a negative right can be avoided by a move to a positive moral right to reproductive liberty (PMRRL), as supported by the capabilities approach. PMRRL holds that:

Individuals possess not only the moral right to make reproductive choices free from government interference, but the right to support in making that choice: the exercisable freedom to make decisions surrounding their own reproduction (whether this be the prevention or pursuit of reproduction).

As a positive right, PMRRL is more demanding than negative conceptions, placing moral obligations on third parties to facilitate reproductive decision-making. It may require governments to provide financial support, a wider geographic distribution of clinics, increased education around reproductive services, and efforts to enact changes in societal attitudes towards certain groups whose reproductive choices are disvalued. I argue that although the positive right demands much of governments, this does not constitute an overwhelming argument against the moral right itself, but rather a consideration to be taken into account in application of the right in practice.

The emphasis on both the prevention and pursuit of reproduction in PMRRL maintains the importance of being able to exercise both choices to prevent reproduction via adequate access to contraceptives and abortion, and choices to pursue reproduction via adequate access to ARTs. In this latter area, positive right conceptions standardly argue for the importance of the choice to have a child (using IVF), without focusing on the relevance to reproductive decision-making of the type of child that prospective parents may have-a choice that is made increasingly possible with the advent of genetic selection technologies such as PGD. I leave further discussion of this last 
PRE-PUBLICATION VERSION - For published version, see the Kennedy Institute of Ethics Journal

distinction to my application of PMRRL to accessing ARTs in the final section, but intend my argument for PMRRL up to that point to apply both to choices regarding whether to have a child and what type of child to have.

My basis for justifying PMRRL is different to those traditionally proposed to defend demanding conceptions of reproductive rights in the literature. For example, Ronald Dworkin uses concepts of privacy and even religious freedom to defend the right of the individual "to control their own role in procreation unless the state has a compelling reason for denying them that control" $(1993,148)$. Privacy may justify one's bodily integrity not being threatened (by being made to carry a child instead of being offered accessible abortion services); however, it does not provide an adequate basis for defending access to ARTs as part of the choice to reproduce. A woman's privacy and bodily integrity is, if anything, impinged by use of ARTs, though as long as they are administered with her consent, such concerns have less moral relevance. The privacy argument clearly has no place in defending reproductive choices to reproduce. Instead, I refer to the capabilities approach to develop and defend PMRRL.

One way in which my conception differs from some of its predecessors is in its recognition of power as inherent to the idea of freedom. The individual's ability as to make self-affecting, valued life decisions is essential to modern ideas of freedom (Pettit 2006; Skinner 2008). If one lacks power relevant to enact a particular choice, one is effectively deprived of that theoretical freedom to choose. Reproductive choice and the use of ARTs as 'technologies of power' is one way in which power is affirmed via the self-definition of individuals whose positive right to reproductive freedom is granted (Mills 2013). In the case of a negative right, individuals who are not already empowered by their position in society are effectively denied yet another road to empowerment via the use of 'technologies of power' that enable their self-definition. Whilst the negative right to reproductive freedom does not recognize how failing to ensure the exercisability of a reproductive right removes this power via self-defining reproductive choices, and thereby denies freedom, a positive right does. The freedom to make choices that allow us to 
PRE-PUBLICATION VERSION - For published version, see the Kennedy Institute of Ethics Journal

define and affirm our identities links both to empowerment, and to a capability-based justification of positive rights. Indeed, it has been claimed that "capabilities are more or less equivalent to empowerment", because they "represent the power of the individual (or group) to avoid harms and pursue valued forms of functioning, including crucially the ability to make reasoned determinations of what is to be valued." (Johnstone 2007, 66-67) In areas such as reproduction, the ability to make these determinations is reliant on two things: the existence of technologies of power that enable choices regarding whether and how to reproduce where these options did not previously exist (such as before the advent of ARTs), and the assurance of access to them and the ability to use them that a positive right provides.

\section{The Capabilities Approach}

The capabilities approach, developed in varying forms by Amartya Sen and Martha Nussbaum, uses the concepts of human flourishing and self-definition to emphasize the importance of certain core exercisable freedoms in our lives (Nussbaum 2000; Sen 1992). It rests on two normative claims, firstly that the ability to pursue flourishing and define one's own identity are of primary moral importance, and secondly that these ideas should be understood in terms of people's capabilities, or their opportunities and power to do whatever they reasonably value as serves the end of flourishing (Robeyns 2016b). The approach claims that in order to not only survive, but lead fulfilling, fruitful lives, we must have exercisable free choice, or 'capabilities', regarding key areas relating to our flourishing, or 'functionings'. Capabilities and functionings are not valued only insofar as the value society places on them, but are rather subjectively assessed by the individual, who knows best their own ends and interests, and how to pursue a flourishing life.

Although not usually applied in rights discourse, the capabilities approach holds promise here. Nussbaum claims that "people differ about what the basis of a rights claim is [...], the best way of thinking about what it is to secure them to people is to think in terms of capabilities" (2003, 
PRE-PUBLICATION VERSION - For published version, see the Kennedy Institute of Ethics Journal

37). The capabilities approach makes it clear that people "don't really have an effective right $[\ldots]$ simply because this language exists on paper". Rather, they "really have been given a right only if there are effective measures to make people truly capable of political exercise" (2003, 41). Capabilities effectively encompass what is valuable about a right: not theoretically possessing it, but being able to apply or claim it in valued ways, regardless of whether one is socially, physically, biologically and educationally advantaged or not. Included in Nussbaum's list of central human capabilities that may be appropriate bases for rights are bodily health—that is, "being able to have good health, including reproductive health"—and bodily integrity—-that is, "having opportunities for sexual satisfaction and choice in matters of reproduction" $(2003,41)$. Here, the reference to reproductive choice confirms the centrality of reproductive choice to human flourishing and self-definition, linking the right directly to the capability.

\section{Requirements of the Positive Moral Right to Reproductive Liberty}

The positive moral right imposes requirements on third parties—primarily governments—in order to ensure the exercisable freedom to reproduce for all members of a given society.

Firstly, the right imposes some minimal requirements on members of the public. For individuals whose reproductive choices are not limited by social stigma, financial disadvantage, or other forms of disempowerment in the reproductive decision-making process, reproductive choices are exercisable even under a solely negative conception of the right. These individuals do not require government intervention in order to exercise choice. A positive moral right does not deprive them of this liberty, although it may impose an obligation on them to contribute (via taxation) to supporting the same right for other citizens. Although this is objectionable to neoliberal viewpoints, we generally expect and accept such measures in liberal democratic 
PRE-PUBLICATION VERSION - For published version, see the Kennedy Institute of Ethics Journal

societies where we place on governments the responsibility to provide welfare-enhancing goods for citizens. ${ }^{3}$

Primarily, the right imposes requirements on governments. Those whose reproductive choices are limited in some way often cannot exercise reproductive choice without intervention by governments. Rachel Pine and Sylvia Law assert that governments have the following obligations:

"the obligation to insure that people can make reproductive decisions freely $[; \ldots]$ subsidies for those who cannot afford the means of exercising choice; protection from the hostile acts of private parties seeking to interfere with choice; and educational, medical and social services to facilitate true choice" $(1992,421)$.

Similarly, PMRRL requires such interventions from government to ensure that reproductive choice, contributing to the capabilities of bodily health and bodily integrity, is exercisable for all individuals insofar as their reproductive choices do not threaten harm to others. The capabilities approach also stipulates that the level of support necessary to secure capabilities should be ensured for those with lower 'conversion factors'. Amartya Sen defines these as individuals' abilities to convert a personal, social, or environmental resource into a valued functioning or desired end (1992). Government intervention is required by PMRRL regardless of the origins of individuals' impediments to exercising the right—whether such impediments are the result of brute luck resulting in low fertility, social structures, individuals' previous choices, or third-party hindrance of reproductive choice, governments are equally obliged by PMRRL to aid them.

\footnotetext{
${ }^{3}$ Such goods include those that are essential to human flourishing and self-determination, and may include systems that support health, productivity, the production of knowledge, and safety. Thus, we accept tax contributions for state-supported healthcare systems, education systems, national defence, and necessary supports for labour markets.
} 
PRE-PUBLICATION VERSION - For published version, see the Kennedy Institute of Ethics Journal

Such are the requirements of PMRRL. In some ways, these may appear very demanding, and objections may be raised, which I address below. First, however, let us compare PMRRL to its alternatives.

\section{Comparing the Right to Alternative Conceptions}

The existence of viable alternatives to PMRRL in the literature may be cause us to question whether its development is really necessary-perhaps alternative positive right conceptions that place fewer burdens on taxpayers and governments are both sufficient and less demanding. I hold that PMRRL is able to address essential areas that are not sufficiently addressed by at least one alternative account: Dworkin's positive right to procreative autonomy. These essential areas include: limiting the coercive powers given to governments so as to avoid slippery slopes to authoritarianism; accounting for variations in individuals' resource access and ability to convert resources to desired functionings; and adequate representation of marginalized groups. The comparative weaknesses of alternatives such as Dworkin's in addressing these areas and their resulting problematic outcomes in relation to social justice are significant enough to justify the need for a new approach.

To first introduce an alternative, Dworkin's conception of procreative autonomy confirms a woman's right to decide whether to conceive and bear a child. It is discussed primarily in terms of its implications regarding access to abortion in the United States, however applies more broadly to access to reproductive services, as well. Dworkin points out that “since a woman's right to procreative autonomy is fundamental, we must regard a constraint as undue if it makes exercise of that right all but impossible for some women $[\ldots]$ but even a constraint that $[\ldots]$ makes it sufficiently more expensive or difficult that it will deter some women [...] imposes an "undue" burden if it seems, on balance, designed to have that consequence."(1993, 199) Among such potential burdens, Dworkin lists financial cost, limited geographic distribution of clinics, and waiting-time requirements as unacceptably limiting procreative autonomy. 
PRE-PUBLICATION VERSION - For published version, see the Kennedy Institute of Ethics Journal

In the past, positive liberty conceptions more generally have been criticized for their tendency to justify government overreach into citizens' lives where these citizens are suspected to lack full autonomy in their decision-making, whether this be due to a lack of capacity or lack of information (Christman 1991). Regarding alternative positive conceptions of reproductive choice, this may allow states to impose educational requirements surrounding reproductive choices or impose interventions when an individual's capacity is questionable, in the name of supporting their internal positive liberty. These positive right conceptions may face slippery slope arguments claiming that they imply aspects of individual psychology may interfere with autonomy. As more aspects are defined as interfering with positive liberty, more and more interference is justified to remove these internal constraints. (Robeyns 2016b). This may result, for example, in the marginalization of reproductive choices of those who are perceived to act irrationally (for example, by wishing to use PGD to select for a child who would have a Disability, even where this can be expected to be better for the child overall due, say, to membership of a valued community), or requirements for their re-education.

Certainly, this may be a pitfall of some less delimited positive right approaches. However, in relying on capabilities, PMRRL focusses on internal impediments to reproductive choice only insofar as these are caused directly by external constraints, not internal ones, in accordance with a focus on limitations to autonomous choice as perceived by the individual in question. The subjective valuation of choice means that coercive or intrusive government measures are unjustified, as states are not in a position to determine and act on individuals' means of pursuing a flourishing life. For example, if a disabled woman's decision not to undertake IVF seems to be affected by the explicit and unjustified expectations of her support workers that she not reproduce (as an expression of disvalue of her particular condition, say), then PMRRL may require removal of these externally-induced barriers to her choice. However, it will not assume that if she does wish to undertake IVF and reproduce no matter the risks of her having a child with a disability, her views on the seriousness of the disability, say, represent an internal constraint on her autonomy. 
PRE-PUBLICATION VERSION - For published version, see the Kennedy Institute of Ethics Journal

Interventions based on PMRRL, then, aim not to change the individual's reproductive decisionmaking, but the external factors that may hinder her freedom to engage in it. However, if no such external influences are apparent, any further government action would be unjustified according to PMRRL. This prevents PMRRL from slipping down the slope to justifying government overreach with regard to the autonomous decisions of individuals. ${ }^{4}$

A second objection commonly levelled at alternative positive conceptions of reproductive freedom is that they may be ineffective at achieving their own ends: simply ensuring access to resources for reproduction does not guarantee freedom of reproductive choice. This may apply to Dworkin's procreative autonomy. Different individuals require different types and amounts of resources and other support in order to achieve the desired functioning of reproductive choice. Without a focus on equal freedom to choose rather than equal resources or access (as the capabilities approach provides), the right may fail to adequately recognize other needs than simply the removal of financial limits to free choice (Robeyns 2016b). PMRRL, rather, requires governments to control for other limiting factors such as social stigmatization of certain groups wishing to access reproductive technologies, lack of education surrounding reproduction, structural factors affecting fertility, or location-based limitations. These are limitations that concern not only access to resources, but the ability to apply those resources to enable reproductive choice. Similarly, differing amounts of these resources may be required to guarantee free choice for those with low conversion factors. Although alternative resource-based accounts may ensure equal access to IVF, those with lower conversion factors will not necessarily experience the same freedom to make valued reproductive choices as those with higher conversion factors, due to other factors not accounted for purely by controlled resource distribution. PMRRL accounts for these conversion limitations where alternative, non-capabilitybased conceptions of the positive right fail to acknowledge them.

\footnotetext{
${ }^{4}$ A further example is offered by Nancy Hirschmann, relating to external causes for battered women's desires to stay in threatening abusive relationships (1996).
} 
PRE-PUBLICATION VERSION - For published version, see the Kennedy Institute of Ethics Journal

Finally, the capabilities approach concept of conversion factors also strengthens PMRRL by ensuring it does not exclude vulnerable groups from discussion, an objection to which alternative positive right conceptions may be prone (Anderson 2014; Knight 2017; Purdy 1996b). As Robeyns recognizes, conversion factors allow the approach to ensure that certain vulnerable groups are not "excluded from our theorizing; for example, a theory of well-being should be relevant for both able-bodied and disabled persons" (2016a, 407). Those with lower conversion factors still have reproductive choice, because the capability basis of PMRRL requires government intervention to control for conversion factors by providing the means necessary for individuals to enact valued functionings.

The advantages of PMRRL compared alternative conceptions of the positive right justify its development here.

\section{Objections to the Right}

The most plausible four objections to PMRRL arise at two levels. The first level is practical, and it concerns: 1) resource allocation to support reproductive choice in healthcare; 2) the limits of ARTs in supporting reproductive choice. These objections are about the application of the right in practice. Although I hold that it is not fatal to the conception of a moral right if its application is practically limited, I wish to address such concerns, regardless. At the second level, objections arise regarding the concept of the moral right itself, concerning: 3) Rawlsian perspectives on compensation; and 4) the use of PMRRL to address problems with reproductive choice rather than proposing wider social reform. I address each objection here.

First, let us consider resource allocation. One limitation in the application of PMRRL may be in our ability to prioritize or weight capabilities for policy decision-making in resource-limited settings. ${ }^{5}$ Government funding in healthcare systems is competitive, and objectors to policy

\footnotetext{
${ }^{5}$ I thank anonymous reviewers for raising the objection in this section.
} 
PRE-PUBLICATION VERSION - For published version, see the Kennedy Institute of Ethics Journal

based on PMRRL may argue that there is no reason why these resources should be dedicated to ensuring reproductive choice over other healthcare priorities.

Theoretically, even Robertson affirms the importance of governments securing rights related to health and wellbeing, claiming that "as a moral matter, an activity that is so valued that it deserves negative right status should also be provided to those without means" (1995, 233). Accordingly, Robertson sees it as a "limitation of liberalism" that some basic needs are not provided for, though he does not go so far as to renounce his own negative conception of procreative liberty on the basis of this view. Robertson may be highlighting here the difference between theoretical justification of positive rights, and their practical application: in resourcelimited settings, prioritization of some positive rights-fulfilments (in my expression here, some capabilities) over others is required of governments. In terms of the ability of the capabilities approach to address these resource allocation problems, we are initially faced with a conundrum. Reproductive choice links to bodily integrity and bodily health: two capabilities on a list of ten central capabilities proposed by Nussbaum. Nussbaum herself provides little guidance as to how resources might be allocated to securing capabilities among her central list. However, Ingrid Robeyns has both raised this issue (Robeyns 2016a), and proposed some ways of solving it using methods for weighting and aggregating capabilities that may be of use in the application of the capabilities approach to inform policy. In particular, she supports the idea of a "social choice procedure" for determining the comparative importance of various capabilities: "The idea would be to let the relevant group of people decide on the weights $[\ldots]$ by participatory techniques." (Robeyns 2006, 358) However, she notes that for policy settings, "discussion of the relative weights is the substance of political debates." (Robeyns 2006, 358) It is only be reference to individuals' valuation of capabilities that we can determine whether ARTs or, say, a particular cancer treatment ought to be allocated (limited) funding. It is outside the scope of this work to offer empirical analysis of the weights of particular capabilities, but it seems plausible to maintain that reproductive choices are highly valued and may be prioritized over some other parts of 
PRE-PUBLICATION VERSION - For published version, see the Kennedy Institute of Ethics Journal

health capability-categories, or other categories Nussbaum suggests such as play or control over one's environment. This reflects the level of government resources we commonly accept as dedicated to supporting health capabilities. In the US, around 17\% of GDP was dedicated to health spending in 2017 (The World Bank 2020), and globally, the health sector has been expanding disproportionately to general economic expansion $3.9 \%$ growth in health spending globally compared to 3.0\% economic growth globally between 2000 and 2017) (Global Spending on Health: A World in Transition 2019). Within the capability category of health, the centrality of reproductive choice in particular for individuals' lives is reflected in the fierceness of public debate surrounding reproductive rights, with recent examples such as changes to abortion law in Poland and threats to Roe $v$ Wade in the US eliciting significant public outcry (BBC News 2019; BBC News 2020; Walker 2020). If these examples of economic investment and public engagement legitimately demonstrate the importance of reproductive choice to individuals, then allowing resource allocation to be informed by collectively-determined capability weightings seems justified, and one way of solving question surrounding the practical application of PMRRL in policy. Outside of guidance from the capabilities approach weightings, we can expect decisions regarding resource allocation in healthcare systems to also be influenced by considerations surrounding cost-effectiveness, such as how many high-quality life years are saved by prospective health interventions competing with ARTs for government funding (Ashcroft 2005). Integrating in analysis from individual valuations of capabilities with these considerations in fact enhances resource allocation guidance. It does so by better recognizing the value of interventions that enhance quality of life without necessarily extending life or reducing health morbidities (a limitation of many cost-effectiveness approaches such as QALYs frameworks (Ashcroft 2005)). Resource allocation decisions that make no reference to the subjective value of reproductive choice by considering individuals' reproductive choices through lenses such as PMRRL have an impoverished view of the benefit that ensues from funding technologies that enable reproductive choice and fulfil the requirements that a positive right imposes. They may 
PRE-PUBLICATION VERSION - For published version, see the Kennedy Institute of Ethics Journal

therefore tend to de-prioritize funding interventions such as ARTs, even though these interventions can significantly improve citizens' pursuits of flourishing lives.

If we have put the first objection against practical applications of PMRRL to rest, a linked resource-based objection remains, concerning the technological and biological limits on how ARTs can support reproductive choice. Aside from the level of allocating funds to ARTs in comparison to other interventions, we must consider the allocation of funds to support individuals' needs regarding ARTs to enable their reproductive choice. How many cycles of IVF ought each individual be able to access according to PMRRL? Should reproductive choice be extended beyond even genetic selection, to include access to future genome editing technologies? Initially, it seems that PMRRL must answer these questions by advocating unlimited access to IVF cycles, and access to genome editing, due to the emphasis of the capabilities approach on conversion factors. If an individual with a low resource-to-functioning conversion factor requires a lot of support—say, either five IVF cycles for a woman with very low fertility, or a surrogate to carry the child for gay men couples, or access to genome editing technologies for prospective parents wishing to have a child with a specific trait-in order to successfully overcome limits to their reproductive choice, then the approach seems to demand that the state provide them whatever is needed. Such concerns with the practical implications of the positive right ought to be recognized, but do not alone represent an adequate objection to the concept of the moral right itself. In resource-limited settings, it may not be possible to provide the required level of support to enable reproductive choice in all matters for all individuals. Where this is the case, there is simply a need for discussion of feasibility and justice, in resource-limited settings. If it is not possible for a state to provide, for example, five IVF cycles for a woman with low fertility, then the demands of PMRRL in context are tempered by what is possible. There are principles that commonly guide the limits imposed on access to resources. PMRRL requires, in its capability-based discussion of conversion factors, that those whose needs are greater are not 
PRE-PUBLICATION VERSION - For published version, see the Kennedy Institute of Ethics Journal

excluded from efforts to ensure their reproductive choice. However, where supporting their right to reproductive choice has a significant impact by effectively depriving others of the opportunity to access IVF, cost-effectiveness in resource allocation demands that reasonable limits are imposed. Exact limits are dependent on the cost of the ARTs in question, making them difficult to determine a priori. However, deciding what constitutes giving an individual a 'fair go' in funding, in proportion with their conversion factors, balanced with cost-effectiveness considerations may be best done in context by healthcare providers. In this way, individuals with lower conversion factors are still supported proportionally to their need, but limits on what this proportion is in funding terms exist. Practically, this is likely to imply an individual-dependent limit on the number of IVF cycles accessible. It is also likely to count out access to surrogacy or genome editing until such options become financially viable to the extent that they would fall within what is required for a proportional 'fair go' for low-conversion factor individuals.

Regardless of concerns at the practical level regarding resource allocation when PMRRL informs policy, thus far the force of the underlying moral argument that PMRRL presents for enabling reproductive choice remains intact. Let us turn now to objections to the right itself.

Consider a third possible objection to PMRRL. Rawlsian critics may claim that PMRRL should not aim to compensate externally-influenced internal or biological limits to realizing the capability of reproductive choice (Pogge 2002). In recognizing varying conversion factors, the capabilities approach requires intervention on behalf of low-fertility individuals, for example, to secure PMRRL. Traditionally, such biological factors or 'natural endowments' have not been included in Rawlsian accounts of political justice, with the redistribution of social goods, rather, being used as a means to ameliorate injustices arising from genetic endowment. However, there are some indications that this is not because Rawls saw these factors as irrelevant to justice, but simply as outside the sphere of human influence at that point (Cooke 2003; Fox 2007). Now that fertility and heritable genetic conditions are remediable causes of disadvantage, these effectively 
PRE-PUBLICATION VERSION - For published version, see the Kennedy Institute of Ethics Journal

become social goods, and thus, appropriate targets for positive rights. As our circle of influence expands, our possible freedoms expand, along with requirements to support these where possible and where it is necessary for human flourishing. If technology becomes available that remedies infertility by eliminating biological barriers to reproductive choice, then individuals' lack of choice to use these technologies because of societal expectations, their low socioeconomic status, or geographic isolation are each factors that constitute remediable social or structural impediments. Whilst a Rawlsian approach at the time of $A$ Theory of Justice could not demand the equalizing of biological endowment, now that it is possible to do so, reproductive ability has become a social good that the theory indeed does require us to address in distributive terms. Thus, although not traditionally supported according to a Rawlsian approach, PMRRL seems justified in its attention to conversion factors and internal or biological barriers reproductive choice.

A final theoretical objection to PMRRL is that it may be conceived in such a way as to make it ineffective at equalizing freedom of reproductive choice. The claim is that it does so in focusing only on in reproductive choice in a narrow sense, instead of aiming for wider social reform to ameliorate the general disadvantages that vulnerable groups (commonly also those experiencing limited reproductive choice) face. This argument claims that the government funding that PMRRL demands may be better spent addressing the root causes of barriers to reproductive choice (Purdy 1996a). For example, social pressures to (not) reproduce may be the result of root causes including cultural norms, ableism and patriarchal structures in society. Insofar as these problems have broader implications than just limitation of reproductive choice, it may be argued that they are the rightful targets of intervention, and that PMRRL is limited by its neglect of them. Laura Purdy claims that "de-emphasizing IVF to concentrate instead on those social factors is therefore not to abandon infertile women but rather to take a different approach to the problem" (1996a). The objection relies on the assumption that focusing on 
PRE-PUBLICATION VERSION - For published version, see the Kennedy Institute of Ethics Journal

reproductive choice by supporting reproductive services necessarily takes resources away from other initiatives that address the root causes of lack of exercisable reproductive choice. However, this assumption can be challenged on the basis that much of the change that PMRRL requires helps to address root causes of a lack of reproductive choice. Even with regard to supporting ART procedures directly, PMRRL does not hold that support should be only financial. Instead, PMRRL requires a variety of efforts that address restrictions on the exercisability of reproductive choice, because of its basis of the capabilities approach, which demands addressing capability impediments that are not only financial, but social, geographic, etc. The result is that PMRRL requires, among other things, increased education on reproductive and other freedoms for vulnerable groups and those who interact with them such as carers, health care workers, etc. Educating these groups is likely to contribute to their empowerment to exercise reproductive choice, which general empowerment in turn strengthens their choice in other areas. Indeed, an important advantage of PMRRL is that it does condone the resourcing of reproductive services to the detriment to other reproductive choice-enhancing initiatives.

\section{APPLICATION OF THE RIGHT TO REPRODUCTIVE TECHNOLOGIES}

Having rebutted objections to PMRRL, I will now apply it to policy surrounding essential ARTs. I indicated earlier that there are two types of choice identified in the pursuit of reproduction, each of which corresponds to one of the following ARTs: the exercisable choice to have a child requires access to IVF, and the exercisable choice of what type of child to have requires access to PGD. The extension of reproductive rights to this latter choice remains somewhat controversial, however it has been well-defended by both advocates of negative right conceptions, (by Robertson, among others (1994)), and more positive conceptions (Purdy 1996b). Such justifications rest on the centrality of the type of child to parents' choices of whether to reproduce. Where the possibility of having a child with a given trait (whether this be a 
PRE-PUBLICATION VERSION - For published version, see the Kennedy Institute of Ethics Journal

disability, disease or other trait) impacts on parents' flourishing, the centrality of the reproductive choice is clear. This may be through impacts that the future child's potential traits may have on the choice of whether to reproduce, or it may be through the financial, social and emotional impacts that supporting a child with particular traits may have on the parents' flourishing. In the case of each of these reproductive choices, then, in adhering to the capabilities approach aim of human flourishing, PMRRL requires these choices to be exercisable, and thus justifies government-supported access to the corresponding reproductive technologies.

\section{In-Vitro Fertilization}

According to the capabilities approach, the valued functioning of having children, for those who want them (whether fertile or not, now that their condition is remediable using IVF), requires the capability to engage in reproductive choice. This is dependent on varying conversion factors between individuals, thus necessitating further support for those with lower conversion factors to achieve the functioning of (not) reproducing. Insofar as ethical guidance for policy is concerned, the positive moral right imposes duties on governments to provide support systems. For low-fertility individuals and couples who are unable to afford IVF, subsidies ought to be provided to ensure that their financial status in comparison to the cost of IVF does not pose an external limit to their capability to make a free reproductive choice regarding whether or not to have children (Burley 1998; Van Hoyweghen et al. 2009; Warren 1988). Similarly, for those who are unable to access IVF due to geographic distribution of clinics, travel subsidies and accommodation may be required to eliminate these external barriers (Rice and Smith 2001). For those who are discouraged from accessing IVF because their genes are considered undesirable, further education must be funded to ensure that their equal right to reproduction, and the equal value of their reproductive decision-making is recognized by all, reducing the effects of stigmatization on limiting the exercise of the choice whether to reproduce (Purdy 1996a, 1996b; Warren 1988). It should be noted that limits to the number of IVF cycles that are funded may 
PRE-PUBLICATION VERSION - For published version, see the Kennedy Institute of Ethics Journal

still be necessary, according to the cost-effectiveness and 'fair go' principles of resource allocation discussed as potential practical objections to PMRRL, above. PMRRL poses requirements for individuals to contribute to supporting others' reproductive choice, as well. Governments' responsibilities to protect citizens' rights, including PMRRL confer on citizens the requirement to contribute via taxes to supporting this right for all. Tax revenue is then allocated within healthcare systems to interventions including IVF. Such requirements are already in place in countries including Australia, the United Kingdom, Canada and France, where IVF access is included (to various extents) in national healthcare systems (Robertson 1995; Van Hoyweghen et al. 2009).

\section{Preimplantation Genetic Diagnosis}

Building on the application of PMRRL to support facilitated access to IVF, I contend that according to PMRRL, governments are required to support individuals' and couples' access to PGD where they are unable to access it without aid, and where it is necessary to reproductive decision-making that contributes to their flourishing, as discussed earlier. Requirements regarding subsidization, the geographic distribution of clinics offering PGD, and education of vulnerable groups and those caring for them may be be required to ensure that this option is made possible for all. These measures are justified by the significance of genetic traits for some individuals' reproductive decision-making and their later flourishing once a child is born into their family. Indeed, access to PGD contributes not only to the core capabilities of bodily health and reproductive health, but also with regard to the effects of genetic information on future capabilities. Christine Straehle's work applies the capabilities approach to analyze the impact of information-giving capabilities (which could include use of genetic screening as part of PGD in reproductive decision-making) on the range of future capabilities open to an individual (2016). In the case of PGD, if individuals are financially prevented from genetic selecting their child when this is relevant to their decision-making, they are deprived of the information that may affect 
PRE-PUBLICATION VERSION - For published version, see the Kennedy Institute of Ethics Journal

their future (non-reproductive) decisions regarding how to raise their child, where these decisions are affected by the child's traits. If a prospective parent is likely to pass on to their future child characteristics that would prevent them from deciding to have a child (perhaps when they consider the expected wellbeing of the future child), or alter how they would raise this child in future, this is a significant factor influencing the reproductive decision-making process. Examples of cases where access to PGD is relevant to reproductive decision-making are abundant in the literature, where the ability to select against hereditary monogenic conditions such as cystic fibrosis, Huntingdon's disease, and Tay Sachs disease has greatly increased the reproductive opportunities and thus the capability of reproductive choice for individuals who otherwise would be essentially deprived of this freedom (Public Summary Document: Preimplantation Genetic Diagnosis Assessment 2017).

It has been objected that individuals would be coerced into using reproductive technologies to shape their reproductive choices according to society's valuation of them, if access to PGD were guaranteed by PMRRL. The 2002 case of British couple Sharon Duchesneau and Candy McCullough provides a pertinent example. Their use of PGD to select for a deaf child to join their deaf family and community caused public outrage (Spriggs 2002), and currently such uses of PGD are not permitted in the United States. However, this objection may speak more against the introduction of subsidized PGD without concurrent education, than against PMRRL directly. Julian Savulescu and Guy Kahane have noted that the possible detriment of being born with a genetic condition can conceivably be outweighed by associated benefits of being more connected to one's family, or groups/communities with that condition, thus being in the interests of the future child, overall (2009). The capabilities approach stresses that functionings are considered valuable according to the value that each individual places on them, as opposed to society's valuation. The plurality inherent in the approach means that PMRRL, so long as it adheres to its capability basis, does not coerce vulnerable groups to undertake PGD, because the 
PRE-PUBLICATION VERSION - For published version, see the Kennedy Institute of Ethics Journal

support that is necessarily included as part of PMRRL includes education to work against the devaluing of vulnerable groups' choices.

PMRRL supports access to both IVF and PGD, and mandates government intervention to ensure that barriers, whether social, economic or structural, are removed, and individuals are practically able to pursue their reproductive goals insofar as states are able to ensure this.

\section{CONCLUSION}

John Robertson's perception of reproductive rights supports the individual use of reproductive technologies such as IVF and PGD, where independently available, to support reproductive decision-making. However, he does not argue for government intervention to ensure the exercisability of such a right. This negative right conception leaves significant proportions of society without the effective right to reproductive choice, which exacerbates current unfair social inequalities, precludes vulnerable groups from making reproductive decisions, and fails to ensure human flourishing or impose appropriate responsibilities upon governments to ensure the wellbeing of their citizens.

Existing positive conceptions of a right to reproductive choice require further development in order to better consider the perspectives of other marginalized groups, and suggest in concrete terms how their rights can also be secured. The capabilities approach presents a solution to this problem, and grounds my conception of PMRRL. Its pluralist account, captured in concepts such as core capacities and conversion factors, and its inherent provision of wider-scale support that is not only financial, are each clear advantages of the approach.

When applied to the specific issue of access to IVF and PGD, PMRRL justifies the financial, geographic, and social government facilitation of access to these reproductive technologies for those unable otherwise to access them. This does not apply when overriding concerns such as expected harm from choosing a particular future child, or the limits on government funding 
when considering justice in resource allocation and reasonable limits to a 'fair go' affect whether securing reproductive choice is feasible or justifiable. This conception provides a promising direction for further development of the right to reproductive choice, and its integration into policy.

Reference List

Anderson, Joel. 2014. Autonomy and Vulnerability Entwined. In Vulnerability: New Essays in Ethics and Feminist Philosophy, eds. Catriona Mackenzie, W Rogers, and Susan Dodds, 134-161. New York: Oxford University Press.

Ashcroft, Richard E. 2005. Quality of Life as the Basis of Health Care Resource Allocation: A Philosopher's Perspective on QALYs. The virtual mentor: VM 7 (2).

BBC News. 2019. In Pictures: Protests across US against abortion bans. Available at: https://www.bbc.com/news/world-us-canada-48361312.

BBC News. 2020. Poland Abortion: Voices of Poles divided over near-total ban. Available at: https://www.bbc.com/news/world-europe-54716994.

Burley, J. 1998. The Price of Eggs: Who Should Bear the Costs of Fertility Treatments? In The Future of Human Reproduction, eds. J Harris, and S Holm, 127-149. Oxford: Oxford University Press.

Christman, John. 1991. Liberalism and Individual Positive Freedom. Ethics 101(2):343-359.

Cooke, Elizabeth F. 2003. Germ-line Engineering, Freedom, and Future Generations. Bioethics $17(1): 32-58$. 
PRE-PUBLICATION VERSION - For published version, see the Kennedy Institute of Ethics Journal

Copelon, Rhonda. 1990. Losing the Negative Right of Privacy: Building Sexual and Reproductive Freedom Nation Institute Conference: The Supreme Court and Daily Life: Who Will the Court Protect in the 1990s. New York University Review of Law \& Social Change 18:15-50.

Dworkin, R. 1993. Life's Dominion: An Argument About Abortion, Euthanasia, and Individual Freedom. New York: Alfred A. Knopf.

Fox, Dov. 2007. Luck, Genes, and Equality. Journal of Law, Medicine \& Ethics 35 (4):712-726.

Global Spending on Health: A World in Transition. 2019. In WHO/HIS/HGF/HF

WorkingPaper/19.4: World Health Organization.

Hirschmann, Nancy J. 1996. Toward a Feminist Theory of Freedom. Political Theory 24 (1):46-67.

Johnstone, Justine. 2007. Technology as empowerment: a capability approach to computer ethics. Ethics and information technology 9 (1):73-87.

Knight, Amber. 2017. Disability and the meaning of reproductive liberty. Politics, Groups, and Identities 5 (1):67-83.

Meilaender, G. 1995. Products of the Will: Robertson's Children of Choice. Washington and Lee Law Review 52 (1):173-195.

Mills, Catherine. 2013. Reproductive Autonomy as Self-Making: Procreative Liberty and the Practice of Ethical Subjectivity. The Journal of Medicine and Philosophy: A Forum for Bioethics and Philosophy of Medicine 38 (6):639-656.

Nussbaum, Martha. 2000. Women and Human Development: The Capabilities Approach. Cambridge: Cambridge University Press.

Nussbaum, Martha. 2003. Capabilities as Fundamental Entitlements: Sen and Social Justice. Feminist Economics 9 (2-3).

Pettit, Philip. 2006. Freedom in the market. Politics, Philosophy \& Economics 5 (2):131-149. 
PRE-PUBLICATION VERSION - For published version, see the Kennedy Institute of Ethics Journal

Pine, Rachael N., and Sylvia A. Law. 1992. Envisioning a Future for Reproductive Liberty: Strategies for Making the Rights Real Symposium: The State of Civil Liberties: Where Do We Go From Here. Harvard Civil Rights-Civil Liberties Law Review 27:407-464.

Pogge, Thomas. 2002. Can the Capability Approach Be Justified? Philosophical Topics 30 (2):167228.

Public Summary Document: Preimplantation Genetic Diagnosis Assessment. 2017. Australian Government Medical Services Advisory Committee.

Purdy, L. 1996a. Children of Choice: Whose Children? At What Cost? In Reproducing Persons: Issues in Feminist Bioethics, 216-230. New York: Cornell University Press.

Purdy, L. 1996b. Loving Future People. In Reproducing Persons: Issues in Feminist Bioethics, 50-74. New York: Cornell University Press.

Rawls, John. 1999. A Theory of Justice. Revised Edition Aufl. Cambridge, MA: Cambridge University Press.

Rice, Nigel, and Peter Smith. 2001. Ethics and geographical equity in health care. Journal of Medical Ethics 27:256-261.

Roberts, Dorothy E. 1995. Social Justice, Procreative Liberty, and the Limits of Liberal Theory: Robertson's "Children of Choice". Law \& Social Inquiry 20 (4):1005-1021.

Robertson, John A. 1994. Children of Choice : Freedom and the New Reproductive Technologies. Princeton: Princeton University Press.

Robertson, John A. 1995. Liberalism and the limits of procreative liberty: A response to my critics. Washington and Lee Law Review 52 (1):233.

Robeyns, Ingrid. 2006. The Capability Approach in Practice. Journal of Political Philosophy 14 (3):351-376. 
PRE-PUBLICATION VERSION - For published version, see the Kennedy Institute of Ethics Journal

Robeyns, Ingrid. 2016a. Capabilitarianism. Journal of Human Development and Capabilities 17 (3):397414.

Robeyns, Ingrid. 2016b. The Capability Approach. In Stanford Encyclopedia of Philosophy, ed. Edward N Zalta.

Savulescu, Julian, and G. U. Y. Kahane. 2009. The moral obligation to create children with the best chance of the best life. Bioethics 23 (5):274-290.

Sen, Amartya. 1992. Inequality Reexamined. Oxford: Clarendon Press.

Skinner, Quentin. 2008. A Genealogy of Liberty, ed. The Doreen B. Townsend Center for the Humanities: UC Berkeley Events (youtube channel). Available at: https://www.youtube.com/watch?v=ECiVz_zRj7A.

Spriggs, M. 2002. Lesbian couple create a child who is deaf like them. Journal of Medical Ethics 28 (5):283..

Straehle, Christine. 2016. Vulnerability, Health Agency and Capability to Health. Bioethics 30 (1). Van Hoyweghen, Ine, Klasien Horstman, Rein Vos, and Erik Aarden. 2009. Providing preimplantation genetic diagnosis in the United Kingdom, The Netherlands and Germany: a comparative in-depth analysis of health-care access. Human Reproduction 24 (7):1542-1547.

The Guardian. 2020. The Price of Choice - The fight over abortion in Poland. Available at: https://www.theguardian.com/world/2020/oct/23/the-price-of-choice-the-fight-overabortion-in-poland-photo-essay.

The World Bank. 2020. Current Health Expenditure. Sourced from The World Health Organization Global Health Expenditure Database. Avaialble at: https://data.worldbank.org/indicator/SH.XPD.CHEX.GD.ZS?name_desc=true. Warren, MA. 1988. IVF and Women's Interests: An Analysis of Feminist Concerns. Bioetbics 2 $(1): 37-57$. 
PRE-PUBLICATION VERSION - For published version, see the Kennedy Institute of Ethics Journal

World Population Policies 2013. 2013. In Economic and Social Affairs, UN Department of Economic and Social Affairs, Population Division. New York: United Nations. 